\title{
Medical genomics research at BGRS-2018
}

\author{
Ancha V. Baranova ${ }^{1,2}$, Vadim V. Klimontov ${ }^{3}$, Andrey Y. Letyagin ${ }^{3}$ and Yuriy L. Orlov $3,4^{*}$ \\ From 11th International Multiconference "Bioinformatics of Genome Regulation and StructurelSystems Biology" - BGRSISB- \\ 2018 \\ Novosibirsk, Russia. 20-25 August 2018
}

This Special Issue of BMC Medical Genomics collates the papers presented at the biannual summit in Bioinformatics and Systems Biology BGRS ISB (Bioinformatics of Genome Regulation and StructurelSystems Biology) - 2018 (http://conf.bionet.nsc.ru/bgrssb2018/en/). This international conference takes place in Novosibirsk since 1998. To accompany this Special Issue, other Special Issues in the fields of genomics, bioinformatics, plant biology, evolutionary biology and systems biology are published as a part of following series: BMC Genomics, BMC Bioinformatics, BMC Systems Biology, BMC Genetics, BMC Evolutionary Biology and BMC Plant Biology [1-4]. In year 2017, respective highlights were organized into the Special Issues with reports from Belyaev Readings-2017 (http:// conf.bionet.nsc.ru/belyaev100/en) [5-8].

The papers comprising this issue of $\mathrm{BMC}$ Medical Genomics were discussed at the BGRS\SB-affiliated symposium "Systems Biology and Biomedicine" (SBioMed-2018) (http://conf.bionet.nsc.ru/ishg2018/en/). A brief summary of these papers is outlined below.

We open up this Special Issue with an interesting report of a negative finding. After applying a variety of high-throughput technologies such as whole-exome sequencing, transcriptome and miRNA analysis, Alexander Lavrov [9] and his team did not find any reliable molecular markers for early prediction of primary resistance or intolerance to imatinib in adult patients with chronic myeloid leukemia (CML). This report contributes to the body of the literature demonstration a lack of consensus between the signatures describing primary responders and non-responders among CML patients $[10,11]$ and points at shortcoming of current approaches [12] for identifying diagnostic and prognostic biomarkers of human diseases.
The following papers utilized high-throughput biomarker discovery approach for extracting insights concerning tumorigenesis. Jun $\mathrm{Lu}$ and co-authors [13] demonstrated that the treatment of non-small cell lung cancer (NSCLC) with anlotinib, a promising tyrosine kinase inhibitor that targets vascular endothelial growth factor receptor (VEGFR), fibroblast growth factor receptor (FGFR), platelet-derived growth factor receptors (PDGFR), and c-kit, may result in the development of resistance due to induction of macrophage inflammatory protein 2-alpha cytokine encoding gene CXCL2, which is involved in wound healing, cancer metastasis, and angiogenesis. Anna Kudryavtseva et al. [14] continue discussion on cancer studies by analysis of mutations in carotid body tumor. Carotid body tumor (CBT) is a rare neoplasm arising from carotid paraganglion in the head and neck [15]. This tumor is heterogeneous and could be associated with both germline and somatic variants. Molecular mechanisms of CBT development are not fully understood. The authors performed exome sequencing of tumors with paired lymph node tissues and peripheral blood obtained from the CBT patients. Mutation load was estimated as the number of somatic variants per megabase of the target regions covered by the Illumina library preparation kit. This work continues previous studies of the authors group on cancer cells presented after Belyaev conference - 2016 [16]. Here Kudryavtseva and colleagues estimated mutation spectra and identified pathogenic somatic and germline variants in the patients.

Elena Voropaeva et al. [17] comprehensively explored variability in TP53 in samples of diffuse large B-cell lymphoma (DLBCL) to show that two sequential inactivation events within that well-known tumor-suppressor locus are required for malignant transformation.

Darya Skuratovskaya and her colleagues [18] profiled mtDNA copy number in various adipose tissue compartments and in peripheral blood mononuclear cells (PBMCs) of obese individuals with and without type 2 
diabetes to show a possibility that the influence of proinflammatory factors may engage compensatory increases in mitochondrial metabolism. On the other hand, elevation of mtDNA copy number was associated with a decrease in secretion of chemerin, known adipokine implicated in autocrine / paracrine signaling stimulating lipolysis. The issue is complicated by the relationship between mtDNA copy number in insulin-dependent tissues to the levels of the biomarkers of endothelial dysfunction and inflammation, which was uncovered by Larisa Litvinova and co-authors [19]. Their work shows that in patients with obesity, systemic subclinical inflammation is paralleled with an increase in mtDNA copies and underlying disturbances of carbohydrate and lipid metabolism.

Peter Sparber and co-authors [20] performed a comprehensive review of involvement of long non-coding RNAs in hereditary diseases in humans, with an emphasis on their mechanistic connections to the development of particular pathophysiological processes spanning OMIM entities from well-known Mendelian disorders to the diseases of imprinting and to the common age-associated conditions like Alzheimer's. Authors thoroughly review a role of pathogenesis-associated lncRNA in the recruitment of chromatin-modifying complexes, antisense transcription, splicing regulation, miRNA processing, RNA-RNA duplex formation and others.

Nikolay Zernov and Mikhail Skoblov [21] presented thorough review of genotype-phenotype correlations in facio-scapulo-humeral muscular dystrophy (FSHD), which is due ectopic expression of the transcription factor DUX4 in skeletal muscles, and identified a set of genetic and epigenetic modifiers for this condition. Understanding of the systems biology of this important condition is crucial for the success of future clinical trials.

Sergey Kulemzin and colleagues [22] set upon increasing our understanding of the mechanisms of chimeric antigen receptors (CAR) activation in $\mathrm{T}$ and NK cells by comparing cell-specific functionalities of several activation-inducible promoters. In activated $\mathrm{T}$ cells, a variant of CD69 promoter was pinpointed as the most potent driver of the expression of engineered mRNAs, while 10xNFkB performed in $\mathrm{T}$ and NK cell with equal power. Unfortunately, the latter promoter has also leaked in absence of stimulation, thus, remaining a suboptimal choice for expression of exogenous sequences. Hence, the search for NK-cell suitable activation-inducible promoter configurations is not yet over.

Daria Kashirina and other members of international team [23] assembled by Irina Larina and Eugene Nikolaev performed quantitative analysis of blood proteins in samples collected at various stages of space flight. Notably, the levels of calprotectin S100A9, a protein with an important role in the functioning of the endothelium, have increased after the landing, in parallel with that for the proteins of complement coagulation cascade, the acute phase reactants, and the proteases. It seems that acute re-adaptation to the gravity activates an inflammatory response in cosmonauts' hypotrophic muscles.

Vladimir Babenko and colleagues [24] analyzed the FTO gene locus for its haplotype profiles within eighteen $1000 \mathrm{G}$ populations from 4 continental groups. Their study points that this obesity-associated locus evolved rapidly, confirming previously reported evidence of the selective sweep [25], which took place in the transcription factors binding sites-enriched sequences within intron 3 of FTO.

Olga Saik and co-authors [26] employed an Associative Network Discovery System for automated literature mining in the field of biology (ANDSystem), previously described by the same group of authors [27] to prioritize the genes involved in endothelial apoptosis and contributing to lymphedema, an debilitating swelling which is due to defects in lymphatic drainage. There is a hope that experimental analysis of the function of these genes will aid in understanding the lymphedema and development of targeted treatments.

Darya Telegina et al. [28] used well-known strain of senescence-accelerated OXYS rats model [29] to study age-related macular degeneration (AMD) through comparative profiling NGF, BDNF, and their receptors for immunohistochemical localization of in a normal and AMD-like rat retinas, and to confirm that alterations in the balance of neurotrophic factors contribute to the development of AMD.

Hence, we present our readers with a wide array of reports describing recent breakthrough in genomics-driven understanding of a molecular pathophysiology of a variety of human disease, covering a spectrum from Mendelian disorders to chronic multifactorial conditions to cancer. At BGRS-2018, the symposium "Systems Biology and Biomedicine" (SBioMed-2018) was also attended by young scientists who gathered in Novosibirsk for a School "Systems Biology and Bioinformatics" (SBB-2018) (http://conf.bionet.nsc.ru/bgrssb2018/en/school/). In previous years, the materials of SBB Schools were published in Special Issues of BMC as well [30]. We invite our readers worldwide to attend our next event - Systems Biology and Bioinformatics Young Scientists School (SBB-2019) which will be held in Novosibirsk, Russia some time during summer of 2019 (http://conf.bionet.nsc.ru/sbb2019/en/). Medical genomics and genetics researches will be discussed as well at VII Congress of Vavilov Society of Geneticists and Breeders at St.-Petersburg State University in June 2019 (https:// events.spbu.ru/events/genetic-selection-2019). Next year conference BGRS $\backslash$ SB-2020 in Novosibirsk is scheduled to June 2020. 


\section{Acknowledgements}

We are grateful to Professors N.A. Kolchanov and A.V. Kochetov for organization of the multi-conference, "Systems Biology and Biomedicine" symposium and providing platform for international medical genomics research. We thank the Russian Foundation of Basic Research for the conference organization support, Zhejiang bioinformatics Society, China, for logistic support of conference participants, Institute of Cytology and Genetics SB RAS (budget project 0324-2019-0040) and Novosibirsk State University (Russian Ministry of Education and Science) for hosting the conference. Organization of the symposium on evolutionary biology presenting medical genomics reports was supported by the Ministry of Education and Science of the Russian Federation grant \#14.W03.31.0015.

The guest editors of the special issue are grateful to the conference committee members and reviewers who helped in the peer-review of the articles as well as in editing and issue preparation: Tatiana Tatarinova (University of La Verne, USA), Piramanayagam Shanmughavel (Bharathiar University, Coimbatore, India), Juan Gallegos (Baylor College of Medicine, USA), Chunyan Cai (The University of Texas Health Science Center at Houston, USA), Hong Sain Ooi (Aarhus University, Denmark), Sheng Liu (Indiana University School of Medicine, USA), Giuseppe Saglio (Universita degli Studi di Torino Scuola di Medicina, Italy), Dmitriy Atochin (Massachusetts General Hospital, USA), Rüdiger Hehlmann (Universität Heidelberg, Germany), llya G. Serebriiskii (Fox Chase Cancer Center, USA), Jau-Song Yu (Chang Gung University, Taoyuan), Elena Bragina (Research Institute of Medical Genetics, Tomsk, Russia), Irina Ogneva (Institute for Biomedical Problems, RAS Moscow, Russia), Irina Yushenova (Josephine Bay Paul Center for Comparative Molecular Biology and Evolution, Woods Hole, USA), Gong-Hong Wei (Biocenter Oulu, Finland), Anastasia Efimenko and Ivan Senin (Lomonosov Moscow State University, Russia), Igor Rogozin (NIH, USA), Chris Bradburne (Advanced Physics Lab, John Hopkins University, USA), Ted Karginov (University of California, Riverside, USA), Xiaodong Zhao (Shaghai Jiaotong University, China), Mikhail Pyatnitsky (The V.Orekhovich Institute of Biomedical Chemistry, Moscow, Russia), Andrey Simbirtsev (State Research Institute of Highly Pure Preparations, SaintPetersburg, Russia), Massimo Federico (University of Modena and Reggio Emilia, Italy), Alexei Fedorov (University of Toledo, Spain), Oleg Shuvalov (Institute of Cytology, Saint-Petersburg, Russia), Olga Gruzdeva (Kemerovo State Medical Academy, Russia), Andrey Glotov (Saint Petersburg State University, Russia), Monica Colitti (University of Udine, Italy), Hiroaki Mitsuhashi (Tokai University, Japan), as well as Timofey Ivanisenko and Vladimir Babenko (both from Institute of Cytology and Genetics SB RAS, Russia).

\section{Funding}

This article did not receive sponsorship for publication.

\section{About this supplement}

This article has been published as part of BMC Medical Genomics Volume 12 Supplement 2, 2019: Selected articles from BGRSISB-2018: medical genomics. The full contents of the supplement are available online at https:// bmcmedgenomics.biomedcentral.com/articles/supplements/volume-12supplement-2.

\section{Authors' contributions}

AVB and YLO are guest editors of the special post-conference issues and Program Committee members of BGRSISB-2018 conference. WK and AYL are Program Committee members and chairmen of "Systems Biology and Biomedicine" symposium at BGRSISB-2018. All the authors read, revised and approved the final manuscript.

\section{Ethics approval and consent to participate}

Not applicable.

\section{Consent for publication}

Not applicable.

\section{Competing interests}

The authors declare that they have no competing interests.

\section{Publisher's Note}

Springer Nature remains neutral with regard to jurisdictional claims in published maps and institutional affiliations.

\section{Author details}

'School of Systems Biology, George Mason University, Fairfax, VA, USA. ${ }^{2}$ Research Centre for Medical Genetics, Moscow 115478, Russia. ${ }^{3}$ Institute of Cytology and Genetics SB RAS, 630090 Novosibirsk, Russia. ${ }^{4}$ Novosibirsk State University, 630090 Novosibirsk, Russia.

\section{Published: 13 March 2019}

\section{References}

1. Orlov YL, Baranova AV, Hofestadt R, Kolchanov NA. Computational genomics at BGRSISB-2016: introductory note. BMC Genomics. 2016; 17(Suppl 14):996.

2. Baranova AV, Orlov YL. Evolutionary biology at BGRSISB-2016. BMC Evol Biol. 2017;17(Suppl 1):21.

3. Orlov YL, Kolchanov NA, Hofestädt R, Wong L. Editorial - bioinformatics development at the BGRSISB conference series: 10th anniversary. J Bioinform Comput Biol. 2017;15(2):1702001.

4. Orlov YL, Baranova AV, Markel AL. Computational models in genetics at BGRSISB-2016: introductory note. BMC Genet. 2016;17(Suppl 3):155.

5. Orlov YL, Moroz LL, Baranova AV. Neuroscience researches at Belyaev conference-2017. BMC Neurosci. 2018;19(Suppl 1):14.

6. Orlov YL, Baranova AV, Salina EA. Computational plant bioscience at BGRSISB-2016: introductory note. BMC Plant Biol. 2016;16(Suppl 3):243.

7. Orlov YL, Baranova AV, Tatarinova TV, Kolchanov NA. Genetics at Belyaev conference - 2017: introductory note. BMC Genet. 2017;18(Suppl 1):116.

8. Orlov YL, Fernandez-Masso JR, Chen M, Baranova AV. Medical genomics at Belyaev conference - 2017. BMC Med Genomics. 2018;11(Suppl 1):11.

9. Lavrov AV, Chelysheva EYU, Adilgereeva EP, Shukhov OA, Smirnikhina SA, Kochergin-Nikitsky KS, et al. Exome, transcriptome and miRNA analysis don't reveal any molecular markers of TKl efficacy in primary CML patients. BMC Med Genomics. 2019;12(Suppl 2). https://doi.org/10.1186/s12920-019-0481-z.

10. Frank O, Brors B, Fabarius A, Li L, Haak M, Merk S, et al. Gene expression signature of primary imatinib-resistant chronic myeloid leukemia patients. Leukemia. 2006;20(8):1400-7.

11. Villuendas R, Steegmann JL, Pollán M, Tracey L, Granda A, Fernández-Ruiz E, et al. Identification of genes involved in imatinib resistance in CML: a geneexpression profiling approach. Leukemia. 2006;20(6):1047-54.

12. Veytsman B, Wang L, Cui T, Bruskin S, Baranova A. Distance-based classifiers as potential diagnostic and prediction tools for human diseases. BMC Genomics. 2014;15(Suppl 12):S10.

13. Lu J, Xu W, Qian J, Wang S, Zhang B, Zhang L. Transcriptome profiling analysis reveals that CXCL2 is involved in anlotinib resistance in human lung cancer cells. BMC Med Genomics. 2019;12(Suppl 2). https://doi.org/10.1186/ s12920-019-0482-y.

14. Kudryavtseva AV, Lukyanova EN, Kalinin DV, Zaretsky AR, Pokrovsky AV, Golovyuk AL, et al. Mutational load in carotid body tumor. BMC Med Genomics. 2019;12(Suppl 2). https://doi.org/10.1186/s12920-019-0483-x

15. Pellitteri PK, Rinaldo A, Myssiorek D, Gary Jackson C, Bradley PJ, Devaney KO, et al. Paragangliomas of the head and neck. Oral Oncol. 2004;40(6):563-75.

16. Pudova EA, Kudryavtseva AV, Fedorova MS, Zaretsky AR, Shcherbo DS, Lukyanova EN, et al. HK3 overexpression associated with epithelial-mesenchymal transition in colorectal cancer. BMC Genomics. 2018;19(Suppl 3):113.

17. Voropaeva EN, Pospelova TI, Voevoda MI, Maksimov VN, Orlov YL, Seregina OB. Clinical aspects of TP53 gene inactivation in diffuse large B-cell lymphoma. BMC Med Genomics. 2019;12(Suppl 2). https://doi.org/10.1186/ s12920-019-0484-9.

18. Skuratovskaia D, Zalotokin P, Vulf M, Mazunin I, Litvinova L. Interrelation of chemerin and TNF-a with mtDNA copy number in adipose tissues and blood cells in obese patients with and without type 2 diabetes. BMC Med Genomics. 2019;12(Suppl 2). https://doi.org/10.1186/s12920-019-0485-8.

19. Litvinova L, Zatolokin P, Vulf M, Mazunin I, Skuratovskaia D. The relationship between the mtDNA copy number in insulin-dependent tissues and markers of endothelial dysfunction and inflammation in obese patients. BMC Med Genomics. 2019;12(Suppl 2). https://doi.org/10.1186/s12920-0190486-7.

20. Sparber P, Filatova A, Khantemirova M, Skoblov M. The role of long noncoding RNAs in the pathogenesis of hereditary diseases. BMC Med Genomics. 2019;12(Suppl 2). https://doi.org/10.1186/s12920-019-0487-6.

21. Zernov N, Skoblov M. Genotype-phenotype correlations in facioscapulohumeral muscular dystrophy. BMC Med Genomics. 2019; 12(Suppl 2). https://doi.org/10.1186/s12920-019-0488-5. 
22. Kulemzin SV, Matvienko DA, Sabirov AH, Sokratyan AM, Chernikova DS, Belovezhets TN, et al. Design and analysis of stably integrated reporters for inducible transgene expression in human T cells and CAR NK-cell lines. BMC Med Genomics. 2019:12(Suppl 2). https://doi.org/10.1186/s12920-019-0489-4

23. Kashirina DN, Percy AJ, Pastushkova LK, Borchers CH, Kireev KS, Ivanisenko $V A$, et al. The molecular mechanisms driving physiological changes after long duration space 2 flights revealed by quantitative analysis of human blood proteins. BMC Med Genet. 2019; (this issue). https://doi.org/10.1186/ s12920-019-0490-y

24. Babenko V, Babenko R, Gamieldien J, Markel A. FTO haplotyping underlines high obesity risk for European populations. BMC Med Genomics. 2019; 12(Suppl 2). https://doi.org/10.1186/s12920-019-0491-x

25. Liu X, Weidle K, Schröck K, Tönjes A, Schleinitz D, Breitfeld J, et al. Signatures of natural selection at the FTO (fat mass and obesity associated) locus in human populations. PLoS One. 2015:10(2):e0117093.

26. Saik OV, Nimaev W, Usmonov DB, Demenkov PS, Ivanisenko TV, Lavrik IN, et al. Prioritization of genes involved in endothelial cell apoptosis by their implication in 2 lymphedema using an analysis of associative gene networks with ANDSystem. BMC Med Genomics. 2019;12(Suppl 2). https:// doi.org/10.1186/s12920-019-0492-9.

27. Ivanisenko VA, Saik OV, Ivanisenko NV, Tiys ES, Ivanisenko TV, Demenkov PS, et al. ANDSystem: an associative network discovery system for automated literature mining in the field of biology. BMC Syst Biol. 2015;9(Suppl 2):S2.

28. Telegina DV, Kolosova NG, Kozhevnikova OS. Immunohistochemical localization of NGF, BDNF, and their receptors in a normal and AMD-like rat retina. BMC Med Genomics. 2019;12(Suppl 2). https://doi.org/10.1186/ s12920-019-0493-8

29. Stefanova NA, Kozhevnikova OS, Vitovtov AO, Maksimova KY, Logvinov SV, Rudnitskaya EA, et al. Senescence-accelerated OXYS rats: a model of agerelated cognitive decline with relevance to abnormalities in Alzheimer disease. Cell Cycle. 2014;13(6):898-909.

30. Baranova AV, Orlov YL. The papers presented at 7th Young Scientists School "Systems Biology and Bioinformatics" (SBB'15): Introductory Note. BMC Genet. 2016;17(Suppl 1):20.

Ready to submit your research? Choose BMC and benefit from:

- fast, convenient online submission

- thorough peer review by experienced researchers in your field

- rapid publication on acceptance

- support for research data, including large and complex data types

- gold Open Access which fosters wider collaboration and increased citations

- maximum visibility for your research: over $100 \mathrm{M}$ website views per year

At $\mathrm{BMC}$, research is always in progress.

Learn more biomedcentral.com/submissions 